\title{
Strategi Optimasi Sistem Manajemen Risiko Pembiayaan pada Bank Jabar Banten Syariah
}

\author{
Optimization Strategy of Financing Risk Management at Bank Jabar Banten Syariah
}

Adnan Sharif ${ }^{*}$, Abdul Kohar Irwanto ${ }^{2 *}$ dan Tubagus Nur Ahmad Maulana ${ }^{2 *}$

${ }^{1}$ Program Magister Manajemen Sekolah Pascasarjana Institut Pertanian Bogor

${ }^{2}$ Departemen Manajemen, Fakultas Ekonomi dan Manajemen, Institut Pertanian Bogor

\#Jl. Kamper, Kampus IPB Darmaga, Bogor 16680

\begin{abstract}
ABSTRAK
Salah satu indikator keberhasilan suatu bank dalam mengelola risiko pembiayaan adalah tingkat Non Performing Financing (NPF). Pada tiga tahun terakhir tren NPF BJB Syariah terus mengalami peningkatan, maka diperlukan suatu penelitan mengetahui tingkat dan profil risiko yang dihadapi oleh BJB Syariah. Penelitian ini bertujuan untuk: (1) Menganalisis tingkat risiko pembiayaan yang dihadapi oleh BJB Syariah dan (2) Menganalisis, mengkaji pengelolaan dan pengendalian berupa program mitigasi risiko pembiayaan yang dihadapi oleh BJB Syariah. Untuk menganalisis tingkat risiko kredit atau pembiayan yang dihadapi oleh BJB Syariah digunakan metode CreditRisk+, sementara itu untuk mengkaji pengelolaan dan pengendalian risiko pembiayaan digunakan analisis internal dan eksternal, analisis SWOT (Strengths, Weaknesses, Opportunities dan Threats) dan Analytical Hierarchy Process (AHP). Hasil yang didapatkan adalah profil dan tingkat risiko pembiayaan BJB Syariah masih tergolong aman. Hal ini terlihat dari expected loss periode 2012-2014 masih tertutupi oleh Penyisihan Pencadangan Aktiva Produktif (PPAP) yang telah dilakukan oleh BJB Syariah. Strategi yang paling optimum adalah peningkatan peran Direktur dalam membuat kebijakan strategik pembiayan seperti penyebaran portofolio pembiayaan pada sektor-sektor industri yang memiliki prospek usaha cukup sehat, menciptakan penilaian kelayakan calon debitur yang lebih hati-hati dan tepat sasaran serta memperkuat penilaian karakter calon debitur melalui penggunaan biro kredit hingga metode scorecard.
\end{abstract}

Kata kunci: BJB Syariah, risiko pembiayaan, sistem manajemen, strategi optimasi

\section{ABSTRACT}

One of the success indicator for the bank into manage their financing risk is a Non Performing Financing (NPF) level. On the last three years, BJB Syariah's NPF trend keep increased, then be required a research to find out profile and financing risk level that be faced by BJB Syariah. This research has some objective to: (1) Analyzing of financing risk level that be faced by BJB Syariah and (2) Analyzing, reviewing of management such as mitigation program for financing risk that be faced by BJB Syariah. To analyzing financing risk level has been used CreditRisk+ model, meanwhile to reviewing management and financing risk mitigation has been used internal and external analysis, SWOT analysis (Strengths, Weaknesses, Opportunities and Threats) and AHP (Analytical Hierarchy Process). The result from this research is profile and financing risk level of BJB Syariah still quite fit. This matter looks from expected loss period 2012-2014 still can be covered by reserved productive asset that has been done by BJB Syariah. Strategy that needed to be performed as follows enhancement director act to make a financing strategic policy such as financing portfolio spread for industry sectors that has fit prospect, making feasibility valuation for new debtor with more prudent and right on target also strengthen character valuation for new debtor using credit bureau until scorecard method.

Key words: BJB Syariah, financing risk, management system, optimization strategy

\footnotetext{
*) Korespondensi:

Jl. Jalak XIV Blok C5/9 Bintaro Jaya Sektor 2 Komplek DPR RI Tangerang Selatan; Email: adnan.sharif13@gmail.com
} 


\section{PENDAHULUAN}

Bank Jabar Banten (BJB) Syariah pada awalnya merupakan unit usaha syariah dari Bank Pembangunan Daerah (BPD) Jawa Barat. Pada tahun 2010 BJB Syariah mulai mengelola usaha secara mandiri. Sebagai sebuah bisnis yang baru, tentunya BJB Syariah membutuhkan perencanaan komprehensif dan sistematis agar tujuan bisnisnya dapat tercapai. Menurut Idroes (2008) Bank tidak bisa dilepaskan dari aktivitas pembiayaan. Salah satu ukuran keberhasilan suatu bank dalam penyaluran pembiayaan adalah pengendalian portofolio pembiayaan nasabah tidak lancar atau Non Performing Financing (NPF).

Besaran NPF pada tahun 2012 sebesar Rp2.433 juta. Selanjutnya terjadi peningkatan NPF pada tahun 2013 menjadi Rp15.296 juta atau meningkat Rp12.862 juta (529\%) dari tahun 2012, dimana kontribusi terbesar peningkatan NPF diakibatkan satu debitur dengan exposure pembiayaan Rp10,080 juta masuk ke dalam status kolektibilitas 3 (kurang lancar). Sementara peningkatan NPF pada tahun 2014 sebesar Rp17.629 juta (115\%) dari tahun 2013, dimana kontribusi terbesar peningkatan ini berasal dari debitur dengan exposure pembiayaan Rp24,200 juta masuk ke dalam status kolektibilitas 5 (macet). Tren NPF BJB Syariah periode 2012-2014 dapat dilihat pada Gambar 1.

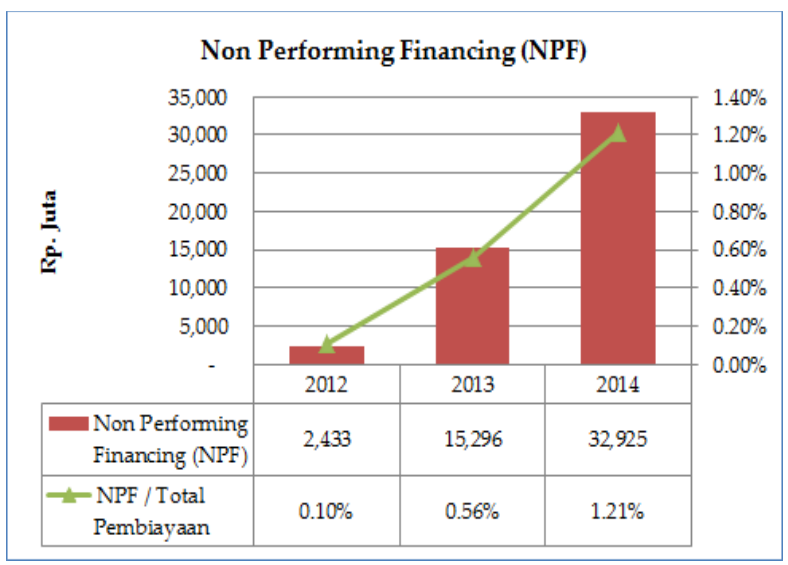

Gambar 1. Tren non performing financing (NPF) periode 2012-2014

Peningkatan tren NPF tersebut dikarenakan BJB Syariah cenderung melakukan ekspansi penyaluran pembiayaan dalam periode 2012-2014, sehingga risiko pembiayaan yang dihadapi juga meningkat setiap tahunnya. Peningkatan NPF dalam tiga tahun terakhir menyebabkan BJB Syariah lebih memperkuat manajemen risiko dan mengedepankan prinsip kehati-hatian dalam penyaluran pembiayaan. Hal ini tentunya menjadi konsen bagi manajemen BJB Syariah dalam menyusun rencana strategik khususnya memperkuat sistem manajemen risiko dan pengendalian risiko pembiayaan.

Mengingat adanya risiko finansial secara langsung yang dihadapi oleh BJB Syariah akibat peningkatan laju NPF, maka dilakukan penelitian tentang profil dan tingkat risiko pembiayaan. Setelah diketahui profil dan tingkat risiko pembiayaan, dilakukan penentuan strategi pengelolaan dan pengendalian risiko guna meminimalisir potensi hilangnya pendapatan yang berdampak pada kinerja keuangan BJB Syariah secara umum. Tujuan penelitian ini adalah (1) Menganalisis tingkat risiko pembiayaan yang dihadapi oleh BJB Syariah, dan (2) Menganalisis, mengkaji pengelolaan dan pengendalian berupa program mitigasi risiko pembiayaan yang dihadapi oleh BJB Syariah.

\section{METODE PENELITIAN}

Penelitian ini dilakukan dari Bulan JanuariMei 2015. Data primer diperoleh melalui pencatatan, pengumpulan data dan wawancara langsung dengan pejabat berwenang yang terkait dengan penyaluran pembiayaan di BJB Syariah. Kegiatan wawancara terhadap pakar dari BJB Syariah dilakukan guna memperoleh informasi untuk menjadi peubah kekuatan, kelemahan, peluang dan ancaman yang dapat digunakan sebagai input untuk alat analisis Strengths, Weakness, Opportunities dan Threats (SWOT) dan Analytical Hierarchy Process (AHP).

Menurut Saaty (1993), analisis AHP digunakan untuk memetakan beberapa pilihan strategi yang berbasis pendapat para ahli. Data sekunder diperoleh melalui data historis BJB Syariah, studi literatur, laporan penelitian dan publikasi elektronik. Jenis data sekunder yang digunakan adalah laporan keuangan BJB Syariah tahun 2010-2014 dan bahan-bahan penunjang yang terkait dengan penelitian.

Menurut Lam (2003), analisis internal risiko pembiayaan atau model portofolio pembiayaan digunakan untuk mengukur risiko pembiayaan dari exposure individual dan menghitung besarnya kerugian yang dihadapi. Menurut Crouhy, Galai dan Mark (2001), metode pengukuran risiko pembiayaan menggunakan CreditRisk+ adalah pendekatan Default Mode, maka data portofolio pembiayaan dikelompokkan dalam kategori Non 
Default (Performing Loan) yang terdiri dari eksposur dengan kolektibilitas lancar dan dalam perhatian khusus dan Default (Non Performing Loan), yaitu eksposur dengan kolektibilitas kurang lancar, diragukan dan macet.

Menurut CSFB (1997) bahwa tahapan yang dilakukan dalam metode CreditRisk+ meliputi: (1) pengelompokan eksposur dalam Band; (2) penghitungan Probability of Default, tahap ini dilakukan dengan menghitung rataan kemungkinan gagal bayar (probability of default) dan standar deviasi (standard deviation) setiap kelompok konsumen; (3) mengukur Expected Loss (EL) atau kerugian akibat gagal bayar yang harus dapat ditutupi oleh provisi. EL merupakan hasil perkalian antara Loss Given Default (LGD) dengan probability of default untuk seluruh kelompok debitur; (4) menghitung Total Expected Loss, total expected loss merupakan penjumlahan dari expected loss tiap band (Hair, Black, Babin dan Anderson, 2009). Expected loss tiap band diperoleh dari penjumlahan expected loss tiap kelas pada band tersebut; (5) menghitung Unexpected Loss (UEL) atau kerugian akibat gagal bayar konsumen yang harus dapat dikendalikan, meskipun tidak diharapkan sebelumnya. Unexpected Loss adalah nilai kumulatif kemungkinan gagal (cumulative probability of default) yang diasumsikan mencapai tingkat keyakinan tertentu (Kollar dan Cisko, 2004); (6) menghitung modal ekonomi (Economic Capital). Economic Capital (EC) adalah modal yang harus dimiliki perusahaan untuk menutupi kerugian maksimum yang disebabkan oleh gagal bayar debitur pada portofolio pembiayaan. EC dalam pengukuran risiko pembiayaan diperoleh dari selisih UEL dan EL; dan (7) uji validitas dengan Back Testing yang direkomendasikan oleh The Basel Committee dengan membandingkan estimasi nilai risiko yang dihitung terhadap nilai risiko sebenarnya (Kung, Wu, HSU, Lee dan Yang, 2009).

Matriks SWOT digunakan untuk menggambarkan secara jelas bagaimana peluang dan ancaman eksternal yang dihadapi dapat disesuaikan dengan kekuatan dan kelemahan yang dihadapi (Wheelen dan Hunger, 2008). Matriks ini menghasilkan empat kemungkinan alternatif strategik. Dalam membentuk matriks SWOT terdapat delapan langkah, yaitu (1) membuat daftar peluang eksternal utama perusahaan, (2) membuat daftar ancaman utama perusahaan, (3) membuat daftar kekuatan internal utama perusahaan, (4) membuat daftar kelemahan internal utama perusahaan, (5) mencocokkan kekuatan internal dengan peluang eksternal dan masukkan hasilnya pada sel strategi SO, (6) mencocokkan kelemahan internal dengan peluang eksternal dan masukkan hasilnya pada sel strategi WO, (7) mencocokkan kekuatan internal dengan ancaman eksternal dan masukkan hasilnya pada sel strategi ST, dan (8) mencocokkan kekuatan internal dengan ancaman eksternal dan masukkan hasilnya pada sel strategi ST (David, 2009).

Penentuan prioritas faktor, aktor, tujuan dan alternatif strategi untuk mengelola dan mengendalikan risiko dilakukan dengan metode AHP. Tahapan dalam metode AHP meliputi; (1) mendefinisikan persoalan dan merinci pemecahan yang diinginkan; (2) membuat struktur hirarki dari sudut pandang manajerial secara menyeluruh; (3) menyusun matriks banding berpasangan; (4) mendapatkan semua pertimbangan yang diperlukan untuk mengembangkan perangkat matriks dilangkah 3; (5) menghitung nilai eigen vector dan menguji konsistensinya, jika tidak konsisten pengambilan data perlu diulangi; (6) mengulangi langkah 3, 4 dan 5 untuk semua tingkat hirarki; (7) menghitung eigen vector dari setiap matriks perbandingan berpasangan. Nilai eigen vector merupakan bobot setiap unsur; (8) mengevaluasi inkonsistensi untuk seluruh hirarki (Saaty, 1993).

\section{HASIL DAN PEMBAHASAN}

\section{Risiko Pembiayaan}

Hasil perhitungan risiko pembiayaan yang diperkirakan terjadi (expected loss) pada tingkat kepercayaan 95\%, dimana terendah tahun 2012 Rp2,855 juta sampai dengan tertinggi tahun 2014 sebesar Rp27,297 juta. Dengan kata lain, potensi terjadinya risiko pembiayaan berkisar $\mathrm{Rp} 2,855$ juta-Rp27,297 juta. Selanjutnya EL dibandingkan terhadap Penyisihan Penghapusan Aktiva Produktif (PPAP) yang telah dibentuk oleh BJB Syariah. PPAP periode 2012-2014 berturut-turut adalah Rp16,423 juta, Rp24,368 juta dan Rp31,708 juta sehingga seluruh EL dalam tiga tahun terakhir masih tertutupi oleh PPAP.

Perhitungan risiko pembiayaan maksimal yang ditanggung perusahaan pada taraf nyata 95\% (unexpected loss) menunjukkan nilai terendah Rp6,430 juta pada tahun 2012 dan tertinggi Rp84,146 juta pada tahun 2014. Hal tersebut menunjukkan potensi risiko pembiayaan maksimum yang dapat ditolerir oleh BJB Syariah berkisar Rp6,430 juta-Rp84,146 juta. EC merupa- 
kan selisih antara Unexpected loss dan Expected Loss (Idroes, 2008). Perhitungan pada Tabel 1 menunjukkan bahwa kecukupan modal yang dibutuhkan berada pada kisaran Rp3,574 juta-Rp56,850 juta. Kondisi ini menunjukkan BJB Syariah mampu menutupi risiko pembiayaan yang diakibatkan oleh unexpected credit default losses walaupun tren NPF terus meningkat dalam tiga tahun terakhir. Hasil perhitungan CreditRisk+ dapat dilihat pada Tabel 1.

Tabel 1. Hasil CreditRisk+

\begin{tabular}{lrrr}
\hline Tahun & $\begin{array}{c}\text { Expected loss } \\
\text { (Rp juta) }\end{array}$ & $\begin{array}{c}\text { Unexpected } \\
\text { loss }\end{array}$ & $\begin{array}{c}\text { Economic } \\
\text { capital } \\
\text { (Rp juta) }\end{array}$ \\
\hline 2012 & 2.855 & 6.430 & 3.574 \\
2013 & 11.055 & 24.949 & 13.893 \\
2014 & 27.297 & 84.146 & 56.850 \\
\hline
\end{tabular}

Sumber: Data Primer Diolah (2015).

Pengujian validitas model dilakukan dengan membandingkan hasil pengukuran data actual default dengan Value at Risk (VaR), yaitu data unexpected loss (Mylonakis dan Diacogiannis, 2010). Berdasarkan hasil uji validitas selama periode waktu pengamatan penelitian mulai tahun 2012-2014 tidak ada nilai actual default yang melebihi VaR yang terlihat pada Gambar 2. Nilai VaR tahun 2014 adalah Rp84,146 juta, artinya dengan tingkat kepercayaan $95 \%$, potensi kerugian maksimum yang dihadapi oleh BJB Syariah adalah sebesar Rp84,146 juta. Hal ini berarti model CreditRisk+ yang digunakan dalam penelitian ini masih valid.

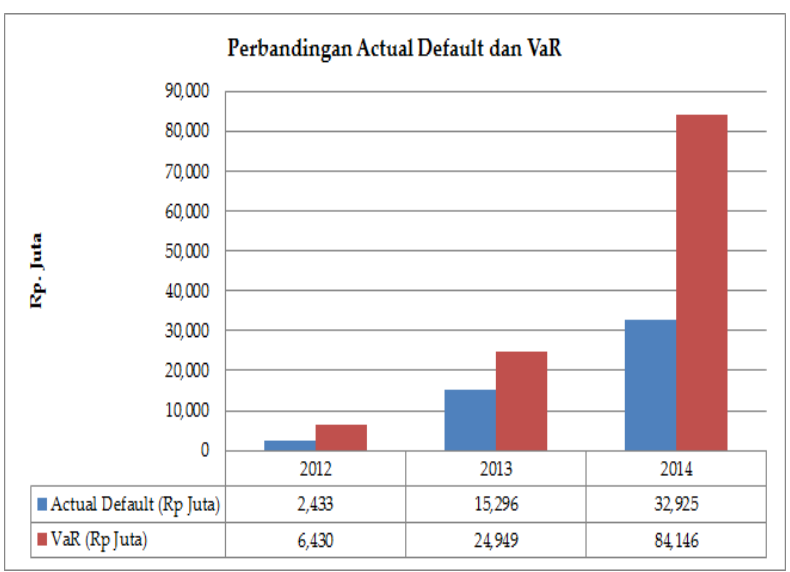

Sumber: Data Primer Diolah (2015).

Gambar 2. Perbandingan actual default dan VaR

\section{Matriks IFE, EFE dan SWOT}

Lingkungan internal BJB Syariah terdiri dari faktor kekuatan dan kelemahan. Skor untuk faktor kekuatan adalah 1.79 dan faktor kelemahan adalah 0.93, sehingga jumlah skor keseluruhan faktor internal adalah 2.73. Skor tersebut menunjukkan posisi internal termasuk dalam kategori sedang. Faktor kekuatan yang memiliki skor paling tinggi atau paling berpengaruh adalah adanya satuan kerja manajemen risiko dan komite pemantau risiko. Satuan kerja manajemen risiko bertugas menetapkan kebijakan dan prosedur proses pembiayaan untuk memastikan profil risiko berada dalam toleransi BJB Syariah. Sementara itu komite pemantau risiko berperan memberikan rekomendasi kepada dewan komisaris untuk memastikan seluruh kebijakan manajemen risiko dilaksanakan dengan baik. Sedangkan faktor kelemahan yang memiliki skor tertinggi adalah persyaratan pembiayaan relatif longgar. BJB Syariah perlu melakukan review atau audit khusus atas persyaratan pembiayaan yang diberikan kepada debitur sehingga risiko pembiayaan dapat dikendalikan pada masa yang akan datang. Hasil pengolahan data kondisi internal BJB Syariah menggunakan matriks IFE dapat dilihat pada Tabel 2.

Lingkungan eksternal BJB Syariah terdiri dari faktor peluang dan ancaman. Skor untuk faktor peluang 1.56 dan faktor ancaman adalah 0.96 , sehingga jumlah skor keseluruhan untuk faktor eksternal 2.52. Skor tersebut menunjukkan posisi eksternal termasuk dalam kategori sedang. Faktor peluang yang memiliki skor tertinggi adalah kebutuhan pembiayaan relatif tinggi. Kebutuhan pembiayaan dari debitur lama maupun debitur baru selalu meningkat setiap tahun seiring dengan pengembangan usaha tiap debitur. Faktor ancaman yang memiliki skor tertinggi adalah kondisi usaha debitur. Kondisi usaha debitur selama pembiayaan berjalan harus dimonitor dengan baik, dikarenakan kondisi usaha debitur berkaitan langsung dengan performa pembayaran kewajiban debitur kepada BJB Syariah. Hasil pengolahan data kondisi eksternal BJB Syariah menggunakan matriks EFE dapat dilihat pada Tabel 3.

Analisis SWOT menghasilkan empat jenis strategi, yaitu strategi SO (Strengths-Opportunities), WO (Weakness-Opportunities), ST (StrengthsThreats) dan WT (Weakness-Threats) (Djohanputro, 2006). Hasil analisis SWOT dapat dilihat pada Tabel 4. 
Tabel 2. Matriks IFE pembiayaan BJB Syariah

\begin{tabular}{|c|c|c|c|c|}
\hline No. & Faktor Internal & $\begin{array}{c}\text { Bobot } \\
\text { (a) }\end{array}$ & $\begin{array}{l}\text { Peringkat } \\
\text { (b) }\end{array}$ & $\begin{array}{l}\text { Nilai tertimbang } \\
(\mathbf{a} \times \mathbf{b})\end{array}$ \\
\hline \multicolumn{5}{|c|}{ Kekuatan } \\
\hline 1 & Pengalaman BJB Syariah dalam menyalurkan pembiayaan & 0,10 & 3,40 & 0,32 \\
\hline 2 & $\begin{array}{l}\text { Adanya satuan kerja manajemen risiko dan komite } \\
\text { pemantau risiko }\end{array}$ & 0,11 & 3,80 & 0,41 \\
\hline 3 & $\begin{array}{l}\text { Sistem informasi manajemen risiko yang membantu dalam } \\
\text { pengelolaan risiko kredit }\end{array}$ & 0,10 & 3,60 & 0,37 \\
\hline 4 & Pertumbuhan portofolio pembiayaan dari tahun ke tahun & 0,10 & 3,60 & 0,34 \\
\hline \multirow[t]{2}{*}{5} & $\begin{array}{l}\text { Tingkat margin pembiayaan yang ditetapkan cukup } \\
\text { bersaing }\end{array}$ & 0,10 & 3,40 & 0,35 \\
\hline & Sub Total & & & 1,79 \\
\hline \multicolumn{5}{|c|}{ Kelemahan } \\
\hline 6 & $\begin{array}{l}\text { Jumlah dan mutu sumberdaya manusia masih kurang } \\
\text { guna menghadapi peningkatan pengajuan pembiayaan }\end{array}$ & 0,10 & 2,00 & 0,191 \\
\hline 7 & Tenor pinjaman yang lama (lebih dari 1 tahun) & 0,09 & 1,80 & 0,16 \\
\hline 8 & Lemahnya proses monitoring pinjaman oleh petugas Bank & 0,11 & 1,80 & 0,195 \\
\hline 9 & Persyaratan pembiayaan relatif longgar & 0,10 & 2,00 & 0,20 \\
\hline \multirow[t]{3}{*}{10} & $\begin{array}{l}\text { Pembiayaan yang terkonsentrasi pada industri atau sektor } \\
\text { tertentu }\end{array}$ & 0,10 & 1,80 & 0,18 \\
\hline & Sub Total & & & 0,93 \\
\hline & Total & 1,00 & & 2,73 \\
\hline
\end{tabular}

Tabel 3. Matriks EFE pembiayaan BJB Syariah

\begin{tabular}{|c|c|c|c|c|}
\hline No. & Faktor Eksternal & $\begin{array}{l}\text { Bobot } \\
\text { (a) }\end{array}$ & $\begin{array}{l}\text { Peringkat } \\
\text { (b) }\end{array}$ & $\begin{array}{l}\text { Nilai tertimbang } \\
(\mathbf{a} \times \mathbf{b})\end{array}$ \\
\hline \multicolumn{5}{|c|}{ Peluang } \\
\hline 1 & $\begin{array}{l}\text { Relatif masih banyaknya UMKM dan non UMKM yang } \\
\text { belum memperoleh akses pembiayaan dari Bank dan } \\
\text { Lembaga Keuangan }\end{array}$ & 0,14 & 3,40 & 0,47 \\
\hline 2 & Kebutuhan akan pembiayaan relatif tinggi & 0,16 & 3,80 & 0,59 \\
\hline 3 & $\begin{array}{l}\text { Adanya Masyarakat Ekonomi Asean (MEA) } 2015 \\
\text { membuka peluang BJB Syariah untuk menjalin kerjasama } \\
\text { dengan lembaga keuangan wilayah Asean dalam hal } \\
\text { penyediaan dan penyaluran dana }\end{array}$ & 0,15 & 3,40 & 0,50 \\
\hline & Sub Total & & & 1,56 \\
\hline \multicolumn{5}{|c|}{ Ancaman } \\
\hline 4 & Kenaikan suku bunga Bank Indonesia & 0,14 & 1,60 & 0,22 \\
\hline 5 & Kondisi usaha debitur & 0,18 & 1,80 & 0,32 \\
\hline 6 & $\begin{array}{l}\text { Adanya persaingan dalam hal penyaluran pembiayaan } \\
\text { untuk UMKM baik dari bank umum konvensional, bank } \\
\text { syariah lain maupun BPR dan BPRS }\end{array}$ & 0,11 & 1,60 & 0,17 \\
\hline \multirow[t]{3}{*}{7} & $\begin{array}{l}\text { Kondisi perekonomian nasional seperti ketatnya likuiditas, } \\
\text { kenaikan inflasi dan perubahan kebijakan pemerintah } \\
\text { maupun perekonomian global yang mempengaruhi } \\
\text { kualitas penyediaan dana dan kecukupan penyediaan dana } \\
\text { untuk masa yang akan datang. }\end{array}$ & 0,14 & 1,80 & 0,25 \\
\hline & Sub Total & & & 0,96 \\
\hline & Total & 1,00 & & 2,52 \\
\hline
\end{tabular}


Tabel 4. Matriks SWOT pembiayaan BJB Syariah

\begin{tabular}{|c|c|c|}
\hline FAKTOR INTERNAL & $\begin{array}{l}\text { Strengths (Kekuatan) } \\
\text { 1. Adanya satuan kerja } \\
\text { manajemen risiko dan komite } \\
\text { pemantau risiko } \\
\text { 2. Sistem informasi manajemen } \\
\text { risiko yang membantu dalam } \\
\text { pengelolaan risiko kredit } \\
\text { 3. Tingkat margin pembiayaan } \\
\text { yang ditetapkan cukup } \\
\text { bersaing } \\
\text { 4. Pertumbuhan portofolio } \\
\text { pembiayaan dari tahun ke } \\
\text { tahun } \\
\text { 5. Pengalaman BJB Syariah } \\
\text { dalam menyalurkan } \\
\text { pembiayaan }\end{array}$ & $\begin{array}{l}\text { Weaknesses (Kelemahan) } \\
\text { 1. Persyaratan pembiayaan } \\
\text { relatif longgar } \\
\text { 2. Lemahnya proses monitoring } \\
\text { pinjaman oleh petugas Bank } \\
\text { 3. Jumlah dan mutu sumber } \\
\text { daya manusia masih kurang } \\
\text { guna menghadapi peningkat- } \\
\text { an pengajuan pembiayaan } \\
\text { 4. Pembiayaan yang terkonsen- } \\
\text { trasi pada industri atau } \\
\text { sektor tertentu } \\
\text { 5. Tenor pinjaman yang lama } \\
\text { (lebih dari } 1 \text { tahun) }\end{array}$ \\
\hline Opportunities (Peluang) & Strengths - Opportunities & Weaknesses - Opportunities \\
\hline $\begin{array}{l}\text { 1. Kebutuhan akan pembiayaan relatif } \\
\text { tinggi. }\end{array}$ & $\begin{array}{l}\text { 1. Peningkatan jumlah dan } \\
\text { portofolio pembiayaan }\end{array}$ & $\begin{array}{l}\text { 1. Memperketat syarat } \\
\text { pemberian pembiayaan }\end{array}$ \\
\hline $\begin{array}{l}\text { 2. Adanya MEA } 2015 \text { membuka peluang } \\
\text { BJB Syariah untuk menjalin kerjasama } \\
\text { dengan lembaga keuangan wilayah } \\
\text { ASEAN dalam hal penyediaan dan } \\
\text { penyaluran dana } \\
\text { 3. Relatif masih banyaknya UMKM dan } \\
\text { Non UMKM yang belum memperoleh } \\
\text { akses pembiayaan dari Bank dan } \\
\text { Lembaga Keuangan }\end{array}$ & $\begin{array}{l}\text { 2. Menjalin kerjasama antar } \\
\text { lembaga keuangan syariah } \\
\text { wilayah ASEAN dalam hal } \\
\text { penempatan dana dan } \\
\text { penyaluran pembiayaan } \\
\text { produktif. } \\
\text { 3. Pembuatan inovasi produk } \\
\text { pembiayaan khusus untuk } \\
\text { UMKM dan Non UMKM. }\end{array}$ & $\begin{array}{l}\text { 2. Membuat standar } \\
\text { kompetensi yang harus } \\
\text { dipenuhi oleh petugas Bank } \\
\text { dibidang pembiayaan } \\
\text { 3. Membuat pelatihan intensif } \\
\text { bagi seluruh petugas Bank } \\
\text { untuk pemenuhan standar } \\
\text { kompetensi pembiayaan }\end{array}$ \\
\hline Threats (Ancaman) & Strenghts - Threats & Weaknesses - Threats \\
\hline $\begin{array}{ll}\text { 1. } & \text { Kondisi usaha debitur. } \\
\text { 2. Kondisi perekonomian nasional, seperti } \\
\text { ketatnya likuiditas, kenaikan inflasi } \\
\text { dan perubahan kebijakan pemerintah } \\
\text { maupun perekonomian global yang } \\
\text { mempengaruhi mutu penyediaan dana } \\
\text { untuk masa mendatang } \\
\text { 3. Kenaikan suku bunga BI } \\
\text { 4. Adanya persaingan dalam hal penya- } \\
\text { luran pembiayaan untuk UMKM baik } \\
\text { dari Bank umum konvensional, Bank } \\
\text { syariah lain maupun BPR dan BPRS }\end{array}$ & $\begin{array}{l}\text { 1. Penilaian risiko yang lebih } \\
\text { komprehensif } \\
\text { 2. Melakukan monitoring dan } \\
\text { evaluasi usaha setiap debitur } \\
\text { per semester } \\
\text { 3. Melakukan analisa peramalan } \\
\text { (Forecasting) tingkat } \\
\text { kesehatan Bank untuk jangka } \\
\text { waktu beberapa tahun } \\
\text { mendatang }\end{array}$ & $\begin{array}{l}\text { 1. Penilaian kelayakan calon } \\
\text { debitur } \\
\text { 2. Membuat kebijakan sektor } \\
\text { usaha yang harus dihindari } \\
\text { oleh BJB Syariah (black list } \\
\text { industry) } \\
\text { 3. Penyaluran pembiayaan } \\
\text { pada segmentasi usaha yang } \\
\text { memiliki tingkat NPF relatif } \\
\text { rendah }\end{array}$ \\
\hline
\end{tabular}

\section{Analisis Pemilihan Alternatif Strategi Pengelolaan Risiko Pembiayaan}

Faktor yang dianggap paling berpengaruh terhadap penentuan strategi manajemen risiko pembiayaan adalah dasar penilaian kelayakan calon debitur (bobot 0,494). Seleksi calon debitur sangat menentukan kelayakan calon debitur memperoleh pembiayaan. Pada posisi kedua, penilaian risiko yang lebih komprehensif dengan (bobot 0,239). Penilaian risiko lebih komprehensif juga menentukan manajemen risiko pembiayaan, karena jika risiko telah dinilai secara komprehensif, maka antisipasi bisa dilakukan lebih baik. Pada posisi ketiga memperketat syarat pemberian pembiayaan (bobot 0,173). Semakin ketat syarat, terutama dalam proses seleksi calon debitur, maka risiko akan semakin kecil. Peningkatan pembiayaan dan portofolio (bobot 0,094) berada di posisi empat.

Aktor yang paling berpengaruh terhadap strategi perusahaan adalah direktur (bobot 0,259). Direktur memiliki peranan paling besar bagi Bank BJB Syariah, karena menentukan rencana besar perusahaan. Pada posisi kedua dan ketiga, adalah pemimpin divisi pembiayaan dan reviewer pembiayaan kantor pusat dengan bobot berturutturut 0,223 dan 0,194. Pemimpin cabang, manajer 
dan account officer berada di posisi empat, lima dan enam dengan bobot 0,$158 ; 0,085$ dan 0,081.

Tujuan yang paling berpengaruh terhadap strategi perusahaan adalah menciptakan penilaian kelayakan calon debitur yang lebih hati-hati dan tepat sasaran (bobot 0,508). Kelayakan calon debitur sangat menentukan karena berhubungan dengan kemampuan calon debitur untuk membayar pinjaman. Tujuan untuk meningkatkan kesiapan dalam hal peningkatan portofolio pembiayaan berada di posisi dua dengan bobot 0,258 . Terakhir adalah peramalan tingkat kesehatan Bank dengan bobot 0,234.

Alternatif strategi pertama yang paling tepat diterapkan BJB Syariah adalah memperketat penilaian karakter calon debitur (bobot 0,293).
Dalam hal ini debitur diperoleh dengan seleksi ketat sehingga diharapkan dapat menjalankan kewajibannya dengan lancar selama masa pinjaman. Alternatif strategi kedua adalah penilaian risiko secara lebih hati-hati, komprehensif serta berlapis (bobot 0,278). Penilaian risiko secara lebih hati-hati, komprehensif dan berlapis merupakan cara untuk meminimalisasi terjadinya risiko pembiayaan yang kemungkinan akan muncul pada saat pembiayaan sedang berjalan. Di posisi tiga adalah syarat pemberian pembiayaan lebih ketat (bobot 0,220 ) dan ekspansi pembiayaan tidak hanya pada sektor tertentu (bobot 0,208 ) berada di posisi 4. Struktur hirarki pemilihan strategi pengendalian risiko pembiayaan BJB Syariah dapat dilihat pada Gambar 3.

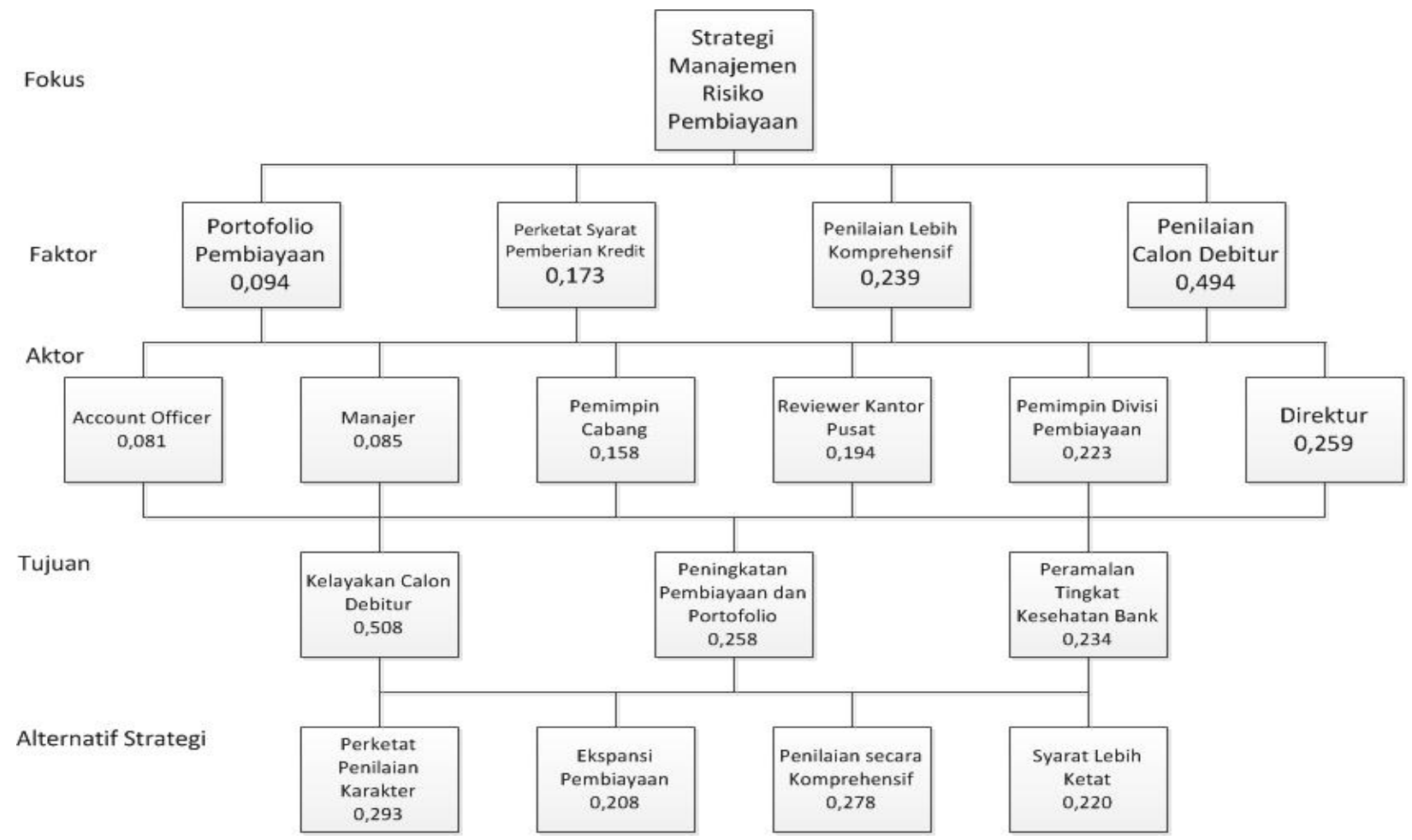

Gambar 3. Struktur hirarki pemilihan strategi pengendalian risiko pembiayaan BJB Syariah

Berdasarkan hasil CreditRisk+, analisis SWOT dan AHP maka diperoleh rekomendasi strategi pengendalian risiko pembiayaan BJB Syariah, antara lain:

1. Bidang Manajemen Risiko

a. Melakukan ekspansi penyaluran pembiayaan pada segmentasi usaha menengah dengan kriteria primer berupa kekayaan bersih tiap nasabah > Rp500 juta-Rp5 miliar, hasil penjualan tahunan tiap nasabah $>$ Rp2,5 miliarRp50 miliar dan pemberian fasilitas pembiayaan tiap nasabah mulai dari Rp500 juta-Rp2 miliar. Hal ini dikarenakan segmentasi usaha menengah adalah segmen dengan tingkat risiko pembiayaan paling rendah dalam periode 2012-2014.

b. Melakukan pembatasan dalam hal penyaluran pembiayaan komersial dan korporasi dikarenakan segmen ini memiliki tingkat risiko pembiayaan paling tinggi dalam periode 2012-2014.

c. Nilai UEL tertinggi pada tahun 2014 sebesar Rp84,146 juta atau 3.10\% dari total eksposur 
pembiayaan tahun 2014, sehingga masih terdapat $4.90 \%$ dari kewajiban penyediaan modal minimum bank yang dapat digunakan untuk ekspansi usaha.

2. Bidang Pembiayaan

a. Berdasarkan hasil SWOT dan AHP diperoleh seperangkat alternatif strategi paling optimum terkait pembiayaan, yaitu analisa kelayakan calon debitur melalui kriteria yang komprehensif, peningkatan peran direktur untuk mendorong ekspansi pembiayaan pada sektor industri yang memiliki prospek cukup sehat, penilaian kelayakan calon debitur lebih hati-hati dan menjadikan penilaian karakter calon debitur sebagai perhatian penting dalam persetujuan pembiayaan.

b. Penilaian karakter calon debitur dapat dilakukan melalui penggunaan Biro Kredit (Credit Burreae) hingga metode scorecard selain metode trade checking yang sudah berjalan.

\section{KESIMPULAN}

1. Perhitungan tingkat risiko pembiayaan dengan metode CreditRisk+ menunjukkan Expected Loss (EL) periode 2012-2014 sebesar Rp2.855 juta-27.297 juta. Tingkat EL tersebut relatif aman karena dapat ditutupi oleh PPAP periode 2012-2014 sebesar Rp16.423 juta-31,708 juta.

2. Dalam rangka pengelolaan risiko pembiayaan, strategi yang dapat dilakukan adalah penilaian kelayakan calon debitur, peningkatan peran direktur dalam pembiayaan, menciptakan penilaian kelayakan calon debitur yang lebih hati-hati dan tepat sasaran, serta memperketat penilaian karakter calon debitur.

\section{DAFTAR PUSTAKA}

[CSFB] Credit Suisse First Boston, (1997). CreditRisk+, a Credit Risk Management Framework.

Crouhy M, Galai D, Mark R. 2000. A Comparative Analysis of Current Credit Risk Model, Journal of Banking and Finance, Vol. 24, 59-117

Crouhy M, Galai D, Mark R. 2001. Risk Management. Mc Graw Hill, New York.

David, F. 2009. Manajemen Strategi (Terjemahan). Salemba Empat, Jakarta.

Djohanputro. 2006. Manajemen Risiko Korporat Terintegrasi. Jakarta (ID) : PPM.

Hair JF, Black WC, Babin BJ, Anderson RE. 2009. Multivariate Data Analysis. Prentice Hall, New Jersey.

Idroes F. 2008. Manajemen Risiko Perbankan. Edisi Pertama. Jakarta (ID) : Raja Grafindo Persada.

Kollar B, Cisko S. 2014. Credit Risk Quantification With The Use Of CreditRisk+. International Conference on Management, Education, Business, and Information Science.

Kung JY, Wu CC, Hsu SY, Lee SW, Yang CW. 2009. Application of Logistic Regression Analysis of Home Mortgage Loan Prepayment and Default Risk. ICIC Express Letters, 4(2), April 2010, 325-331.

Lam, James. 2003. Enterprise Risk Management: Complete Guidance for Direction, Commissioner, and Riks Professional, John Wiley \& Sons, Inc. Hoboken, New Jersey.

Mylonakis J, Diacogiannis G. 2010. Evaluating the Likelihood of Using Linear Discriminant Analysis as A Commercial Bank Card Owners Credit Scoring Model. International Business Research, 3(2), 9-20.

Saaty, T. Lorie. 1993. Pengambilan Keputusan Bagi Para Pemimpin [Terjemahan]. Pustaka Binama Pressindo, Jakarta.

Wheelen, Thomas L. \& J. David Hunger. 2008. Strategic Management and Business Policy. Pearson Education, Inc, Upper Saddle River, New Jersey. 